\title{
Polylactide/poly(hydroxybutyrate-co-hydroxyvalerate) blends: Morphology and mechanical properties
}

\author{
T. Gerard ${ }^{1}$, T. Budtova ${ }^{1}$, A. Podshivalov ${ }^{2}$, S. Bronnikov ${ }^{3 *}$ \\ ${ }^{1}$ Mines ParisTech, Centre de Mise en Forme des Matériaux (CEMEF), UMR CNRS 7635, BP 207, 06904 Sophia \\ Antipolis, France \\ ${ }^{2}$ National Research University of Information Technologies, Mechanics and Optics, Kronverkskiy Prospekt 49, 197101 \\ St. Petersburg, Russian Federation \\ ${ }^{3}$ Russian Academy of Science, Institute of Macromolecular Compounds, Bolshoi Prospekt 31, 199004 St. Petersburg, \\ Russian Federation
}

Received 10 March 2014; accepted in revised form 27 April 2014

\begin{abstract}
The morphology and the mechanical properties of polylactide/poly(hydroxybutyrate-co-hydroxyvalerate) blends of various compositions were studied. The statistical analysis of the scanning electron microscopy images allowed finding two statistical ensembles of the minor-phase particles. The first ensemble involves the dispersed particles, whereas the second one contains the coalesced particles. The mean diameters of both dispersed and coalesced minor-phase particles were calculated and plotted against the blend composition. Young's modulus, tensile strength, elongation at break, and Charpy impact strength of the blends were determined and examined as a function of the blend composition. The Young's modulus values were shown to be in accordance with theoretical predictions.
\end{abstract}

Keywords: polymer blends and alloys, polylactide, polyhydroxyalkanoate, morphology, mechanical properties

\section{Introduction}

Polylactide (PLA) is one of the most widespread biomass-based, biodegradable (compostable) and biocompatible polymers [1, 2]. It is water-insoluble, can be either transparent or semi-transparent depending on polymer crystallinity, and optically active [1, $3]$. It can be processed as a conventional thermoplastic polymer. PLA is used for packaging materials, in agriculture, in textile industry (fibers), in medicine (scaffolds), and in pharmacology (drug delivery systems) $[1,3]$. The main drawbacks of PLA are high brittleness, slow crystallization rate, and high permeability to gases. The ways for overcoming these problems are to use plasticizers, copolymerization with other components, making composites, and blending with other polymers $[1,4]$. The latter allows fabrication of new materials with improved/modi- fied properties. Besides, this way is less expensive than chemical modification or synthesis of tailormade polymers.

If willing to keep PLA-based system fully biodegradable and biocompatible, the second component should also possess these properties. Polyhydroxyalkanoates, aliphatic polyesters, synthesized by microorganisms, are often used as components for blending with PLA and other natural polymers $[5,6]$. The miscibility of PLA and poly(3-hydroxybutyrate) (PHB) strongly depends on both components molecular weight, as expected [7, 8]. For example, using differential scanning calorimetry (DSC) the authors reported that bi-phasic mixtures were obtained when mixing PHB of $M_{\mathrm{w}}=650000 \mathrm{~g} / \mathrm{mol}$ with PLA of $M_{\mathrm{w}}$ above $20000 \mathrm{~g} / \mathrm{mol}$ [8]. Below this value, the polymers were miscible in the whole range of com-

\footnotetext{
${ }^{*}$ Corresponding author, e-mail: bronnik@hq.macro.ru

(C) BME-PT
} 
positions. Bartczak et al. [9] used atactic PHB for making PLA/PHB blends. They found that PLA and PHB form non-miscible or partially miscible blends. They also showed that PHB is well dispersed in the PLA matrix at various ratios and the glass transition temperature of blend decreases with increasing PHB concentration. The impact strength of a thin film of the PLA/PHB blend (80/20 $\mathrm{wt} \%$ ) achieves $120 \mathrm{~kJ} / \mathrm{m}^{2}$ as compared with $50 \mathrm{~kJ} / \mathrm{m}^{2}$ for neat PLA [9].

Another frequently used polymer from polyhydroxyalkanoate family mixed with PLA is poly(hydroxybutyrate-co-hydroxyvalerate) (PHBV). Its properties are known to depend on hydroxyvalerate (HV) content [10]. At very low HV content, PHBV is similar to conventional petrochemical thermoplastics, such as polypropylene, in terms of melting temperature, crystallinity, and tensile strength [11-15]. Most of literature agrees on immiscibility of PLA and PHBV [16-19]. Boufarguine et al. [17] created multilayered films of PLA/PHBV (90/10 wt\%) using multilayer co-extrusion. The formation of highly crystalline thin and long lamellas of PHBV improved gas barrier properties as compared to neat PLA. Foams with various cell densities were produced from PLA/PHBV and PLA/PHBV/clay blends using microcellular injection molding technique [20]. Bicomponent PLA/PHBV fibers were prepared using bicomponent melt spinning [21]. In vitro biocompatibility studies with human dermal fibroblasts demonstrated no toxicity of the fibers making them promising for medical applications.

Because of PLA/PHBV immiscibility, the morphology of most of the blends presents either 'inclusions' of the dispersed phase (usually more or less spherical droplets in the cases of conventional processing) or co-continuous phases. The properties of the blend will depend on the proportion in which in components are mixed, their individual properties, and also on the size distribution of the dispersed phase. In our previous work [18], we reported molten-state rheology of the PLA/PHBV blends and their morphology. The present work is devoted to the detailed analysis and understanding of PLA/PHBV blends characteristics in the solid state: morphology and mechanical properties, both evolving as a func- tion of blend composition. Morphology is investigated using statistical analysis of scanning electron microscopy (SEM) images and analytical description of the histograms of the minor-phase particles' size. Mechanical properties (tensile strength, Young's modulus, elongation at break, and impact strength) are analyzed with the increment of $10 \mathrm{wt} \%$. The elastic properties of blends are compared to the calculated ones according to different theoretical predictions. We also demonstrate that ductile properties of PLA/PHBV blend with PHBV in the minor phase disappear after one month after injection.

\section{Experimental \\ 2.1. Materials}

Both polymers, PLA (3051D, injection molding grade) produced by NatureWorks Co. Ltd., USA, and PHBV (Enmat Y1000P) produced by Tian An Biological Materials Co., People's Republic of China, were provided by Natureplast, France. Their main characteristics, as given by provider, are collected in Table 1.

\subsection{Blends preparation}

PLA/PHBV blends were prepared by components melting in a Haake Rheomix 600 internal batch mixer (Thermo Fisher, Germany), the composition varied from $0 / 100$ to $100 / 0 \mathrm{wt} \%$ with the increment of $10 \mathrm{wt} \%$. The mixing temperature $\left(165^{\circ} \mathrm{C}\right)$, rotor speed $(60 \mathrm{rpm})$, and mixing time (6 $\mathrm{min})$ were chosen according to minimization of PHBV thermal degradation [18]. Because of high viscosity of molten polymers which induced energy dissipation in the mixing chamber, the temperature exceeded the set value by ca. $10^{\circ} \mathrm{C}$ for all blends. The prepared blends were cooled to ambient temperature and cut into granules using an M 50/80 granulator (Hellweg, Germany).

\subsection{Morphology characterization}

The morphology of the blends was studied using a high-resolution scanning electron microscope SUPRA 40 FEG-SEM (Zeiss, Germany). The samples were fractured in liquid nitrogen and sputtercoated with gold-palladium. The obtained images

Table 1. Physical properties of PLA and PHBV as given by provider

\begin{tabular}{|l|c|c|c|c|}
\hline \multicolumn{1}{|c|}{ Polymer } & $\begin{array}{c}\text { Glass transition temperature } \\
{\left[{ }^{\circ} \mathbf{C}\right]}\end{array}$ & $\begin{array}{c}\text { Melting temperature } \\
{\left[{ }^{\circ} \mathbf{C}\right]}\end{array}$ & $\begin{array}{c}\text { Melt flow index, g/10 min } \\
{\left[\mathbf{1 9 0}{ }^{\circ} \mathbf{C} / \mathbf{2 . 1 6} \mathbf{~ k g}\right]}\end{array}$ & $\begin{array}{c}\text { Density } \\
{\left[\mathbf{g} / \mathbf{c m}^{\mathbf{3}}\right]}\end{array}$ \\
\hline PLA & $55-60$ & $145-155$ & $12-20$ & 1.25 \\
\hline PHBV & 5 & $165-175$ & $15-30$ & 1.25 \\
\hline
\end{tabular}


were segmented and processed by digital analysis using UTHSCSA ImageTool 3.0 software (Health Science Center, the University of Texas, San Antonio, USA) resulting in histograms describing minor phase particle size distribution. The histograms were consequently described using the model of reversible aggregation $[22,23]$.

\subsection{Mechanical properties characterization}

Dumbbell-shape tensile bars were obtained from the blends according to ISO 527-2 1BA standard using a Haake Mini Jet II injection molding machine (Thermo Fisher, Germany) at $190^{\circ} \mathrm{C}$. Impact bars were made according to ISO 179 standard by compression moulding using a hydraulic press (Carver, USA).

The tensile properties were measured two days after injection according to ISO 527-1BA standard using a tensile testing machine (Erichsen, Germany) at crosshead speed of $5 \mathrm{~mm} / \mathrm{min}$ at room temperature. For a selected blend, PLA/PHBV $=90 / 10$, the evolution of mechanical properties were followed in time, during one month. Charpy impact strength of the blends was measured using CEAST 9050 (Instron, USA).

\subsection{Background of the model of reversible aggregation}

For statistical analysis of the size distributions of dispersed-phase particles we used the model of the reversible aggregation [22, 23]. The model is based on principles of irreversible thermodynamics and describes microstructure evolution in liquids. According to the model, a stationary microstructure in a liquid permanently fluctuates creating a sequence of the equivalent microstructures, and after liquid freezing, only one of many possible microstructure configurations is realized. The microstructure elements, the aggregates, represent the dynamic units which are permanently composed and decomposed (a condition of reversibility) under thermal fluctuations with energy $k T$ ( $k$ is the Boltzmann constant and $T$ is the absolute temperature). It is supposed that the quasi-stationary equilibrium is quickly reached as a result of self-organization in the system. The model has successfully been applied to different objects and processes, including analysis of morphology of incompatible polymer blends [24-28]. In the model, statistical distribution $h(s)$ of the planar size $s$ of the microstructural entities can be read as Equation (1) [22, 23]: $h(s)=a s^{2} \exp \left(-\frac{s \Delta u_{0}}{k T}\right)$

where $a$ is the normalizing parameter and $\Delta u_{0}$ is the aggregation energy. The latter parameter can be treated as a potential barrier to be overcome for the formation of a statistical ensemble. Its value should rather be compared to the energy of thermal fluctuations: $\Delta u_{0} / k T$.

In some cases, the aggregates form not a single but multiple statistical ensembles. For blended incompatible polymers they are the ensembles of dispersed and coalesced particles [24-28]. In this case, Equation (1) should be read as Equation (2):

$h(s)=\sum_{\mathrm{i}=1}^{\mathrm{N}} a_{1} s_{\mathrm{i}}^{2} \exp \left(-\frac{s_{\mathrm{i}} \Delta u_{0 \mathrm{i}}}{k T}\right)$

where $N$ is the total number of statistical ensembles, while $i$ accounts the number of a statistical ensemble.

As the size parameter $s$ we chose the planar area of the minor phase particles in the SEM images. Equation (2) allows determination of the mean area $<s_{\mathrm{i}}>$ of the minor-phase particles belonging to the $i$ th statistical ensemble as the normalized mathematical expectation $M s_{\mathrm{i}}$ as shown by Equation (3):

$$
<s_{\mathrm{i}}>=M s_{\mathrm{i}}=\frac{\int_{0}^{\infty} s_{\mathrm{i}}^{2} \exp \left(-\frac{s_{\mathrm{i}} \Delta u_{0 \mathrm{i}}}{k T}\right) \mathrm{d} s_{\mathrm{i}}}{\int_{0_{0 \mathrm{i}}}^{\infty} s_{\mathrm{i}}^{2} \exp \left(-\frac{s_{\mathrm{i}} \Delta u_{0 \mathrm{i}}}{k T}\right) \mathrm{d} s_{\mathrm{i}}}=\frac{3 k T}{\Delta u_{0 \mathrm{i}}}
$$

Assuming that the shape of the entities related to the $i$-th statistical ensemble is circular, their mean diameter $\left\langle d_{\mathrm{i}}>\right.$ can be determined using a simple geometrical consideration, see Equation (4):

$$
<d_{\mathrm{i}}>=2 \sqrt{\frac{<s_{\mathrm{i}}>}{\pi}}
$$

\section{Results and discussion}

\subsection{Blend morphology}

In Figure 1, the SEM micrographs of PLA/PHBV blends of various compositions are presented. All images show that blended polymers are immiscible and the particles of the minor phase are well distinguished.

Figure 2 presents the histograms resulting from the statistical analysis of the minor phase particles shown in Figure 1 and their analytical descriptions using Equation (1) or Equation (2). As follows from 


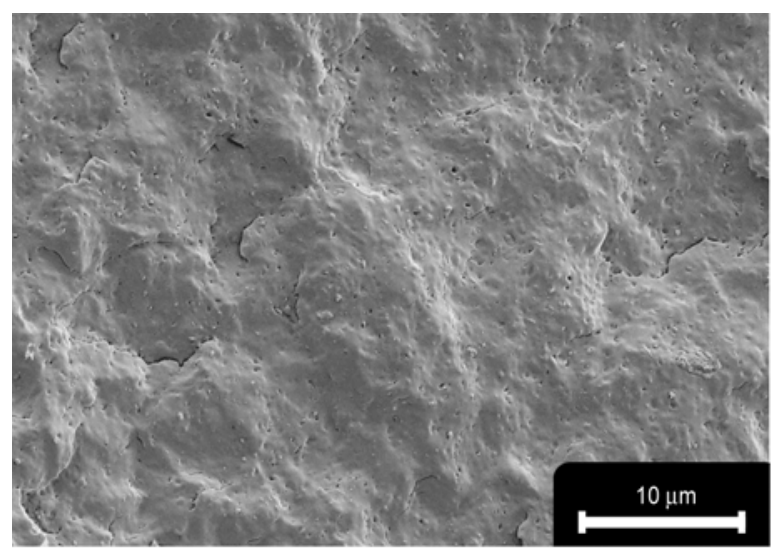

a)

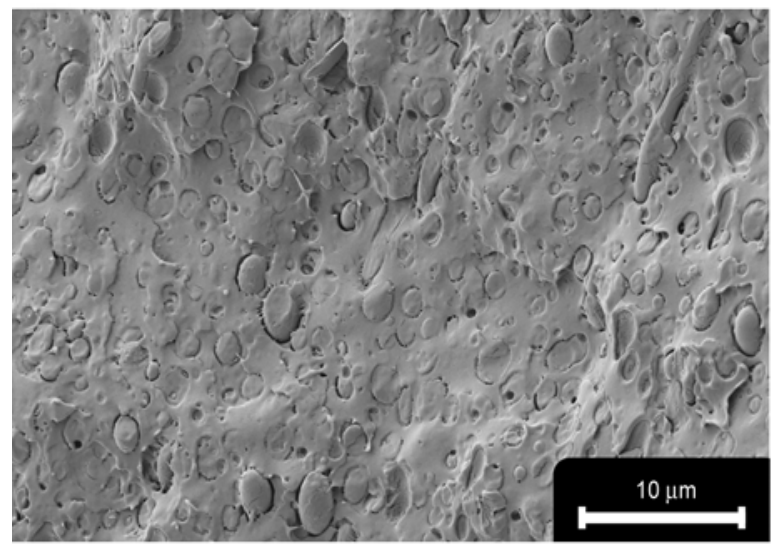

c)

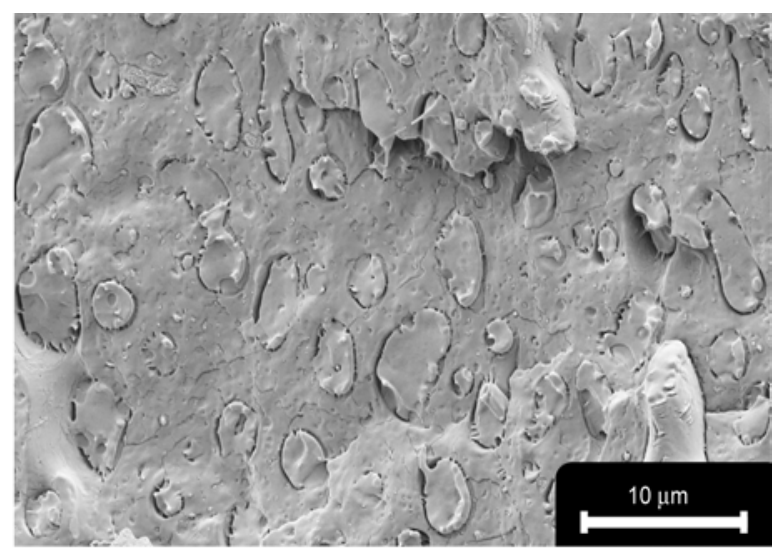

b)

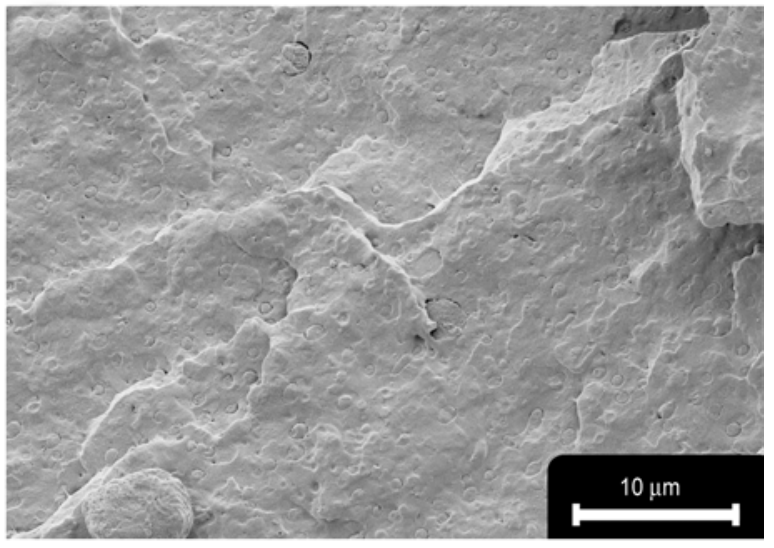

d)

Figure 1. SEM images of the PLA/PHBV blends of the compositions: (a) 10/90, (b) 40/60, (c) 75/25, and (d) $90 / 10$ wt\%

Figure 2, the histograms corresponding to the blends with low PLA content $(\leq 10$ wt \%, see, e.g., Figure 2a) can adequately be described using Equation (1). Similarly, the histograms corresponding to the blends with low PHBV content $(\leq 10 \mathrm{wt} \%$, see, e.g., Figure 2d), can also be successfully described using Equation (1). For the description of the histograms corresponding to the blends with the larger content of the minor component (PLA content $>10 \mathrm{wt} \%$, Figure $2 b$, and PHBV content $>10 \mathrm{wt} \%$, Figure $2 \mathrm{c}$ ), the bimodal distribution (Equation (2), $N=2$ ) rather than Equation (1) is suitable.

Mixing of molten immiscible polymers is known to be accompanied by two processes: i) break-up and dispersion of a minor phase droplets and ii) their coalescence [24-28]. The latter is especially pronounced when no compatibiliser is used. Taking this into consideration, the physical meaning of two statistical ensembles of the minor phase particles observed in Figures $2 b$ and $2 c$ and described with Equation (2) becomes clear: the first ensemble $(i=1)$ contains only the individual dispersed particles, while the second one $(i=2)$ contains exceptionally the coalesced particles.
The mean diameter of both dispersed and coalesced particles belonging to the minor phase was calculated using Equations (3) and (4). In Figure 3, this parameter is plotted as a function of blend composition. In most cases (except PLA/PHBV $=10 / 90$ ), the mean diameter of dispersed PLA and PHBV particles varies from 0.7 to $1.2 \mu \mathrm{m}$; it very slightly increases with increasing minor phase concentration. The mean diameter of the coalesced particles increases more rapidly with increasing minor phase fraction. When the concentration of the minor component exceeds $40 \mathrm{wt} \%$, the mean diameter of the coalesced particles significantly increases: the blend is formed of co-continuous phases (infinite diameter) with some inclusions of individual coalesced droplets. The result obtained is similar to that for the PLA/polystyrene blends [29]. According to the authors, large particles of the minor phase can be explained by weak interactions between the components and their incompability.

\subsection{Mechanical properties}

Tensile and impact properties of the blends of various compositions are presented in Table 2. It shows 

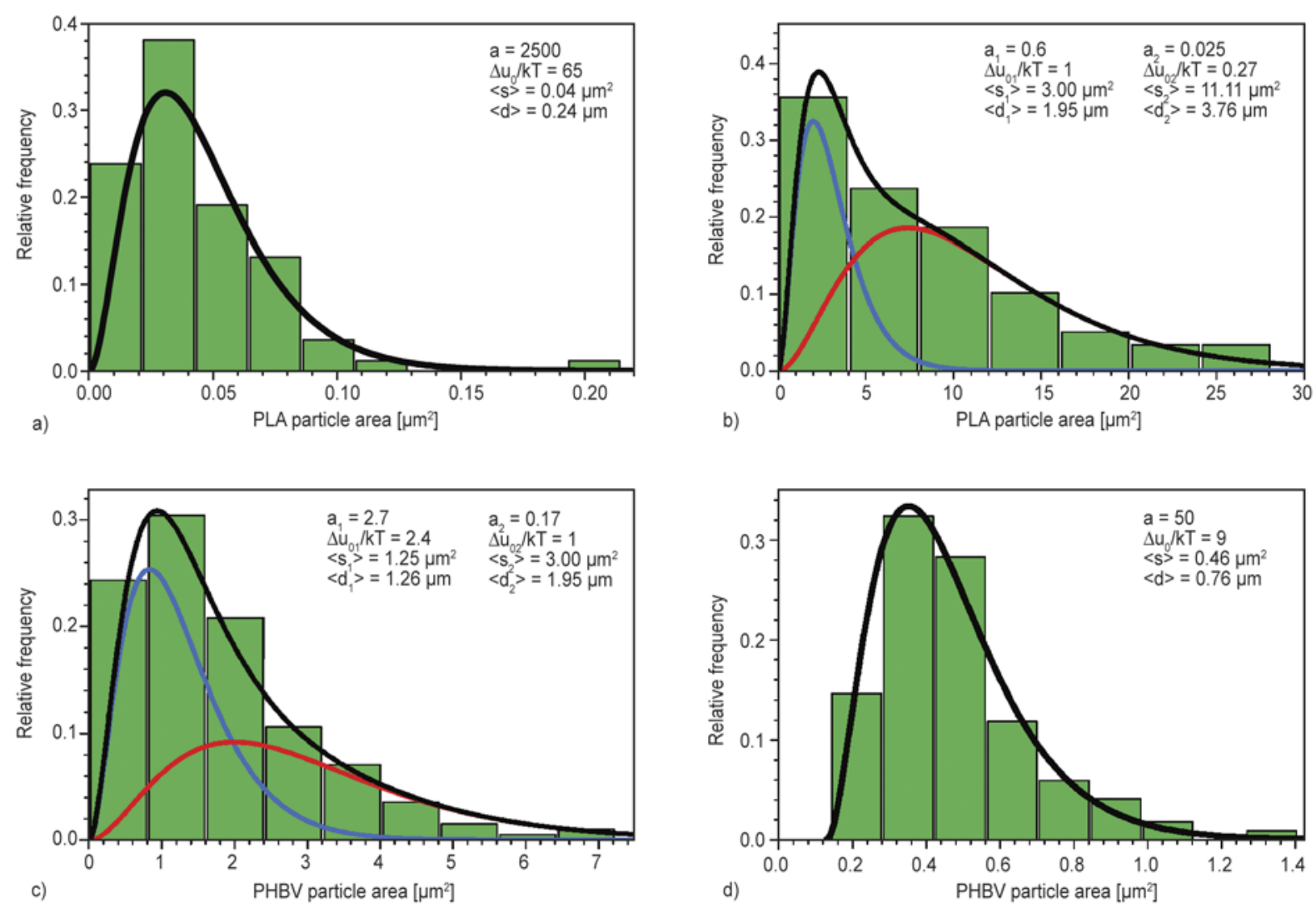

Figure 2. Statistical area distributions of the minor-phase particles in the PLA/PHBV blends of the compositions: (a) 10/90, (b) 40/60, (c) 75/25, and (d) 90/10 wt \%. Their analytical description (black lines) using Equation (1) or Equation (2) $(i=2)$ with the equation parameters presented in boxes is provided along with the mean particle area $\left\langle_{s}\right\rangle$ and mean particle diameter $\langle d\rangle$ calculated with Equations (3) and (4), respectively. In sub-figures (b) and (c), individual statistical ensembles related to dispersed and coalesced particles are presented as blue and red lines, respectively.

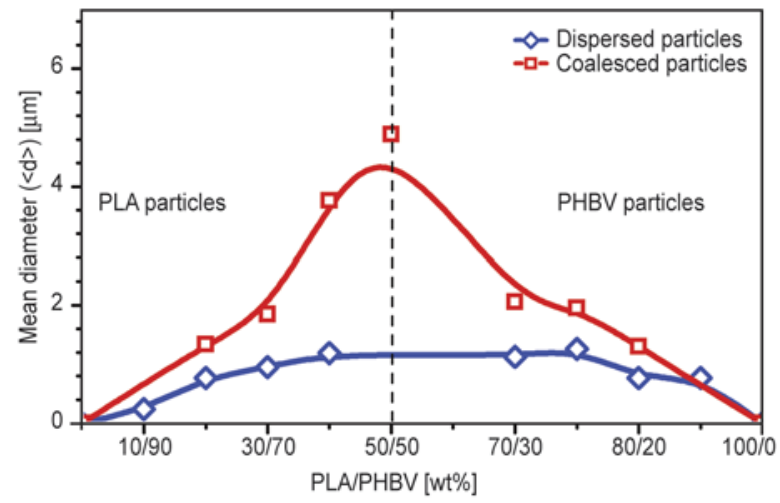

Figure 3. Mean diameter of both dispersed and coalesced minor-phase particles of the PLA/PHBV blends as a function of the blend composition

that both neat components (PLA and PHBV) and the majority of the blends are relatively brittle: their elongation at break varies from 3 to $6 \%$ and impact strength varies from 1 to $2.5 \mathrm{~kJ} / \mathrm{m}^{2}$. Only two PLA/ PHBV compositions, with low content of PHBV, demonstrate high deformability: $50.7 \%$ (80/20 wt $\%)$ and $204 \%$ (90/10 $\mathrm{wt} \%)$. This phenomenon is similar to that reported for PLA blended with some other
PHA-based polymers with the latter being in the minor phase: for example, with poly(3-hydroxybutyrate-co-3-hydroxyhexanoate), so-called 'Nodax' copolymers, the elongation was $100-200 \%$ [30, 31]. It is known that both PLA and PHBV are subjected to aging: for example, PLA loses it ductile properties in 4-5 days at ambient temperature [32] and the mechanical properties of PHBV are stabilized after 20-30 days [33]. We followed the evolution of the elongation at break during one month for PLA/PHBV composition $90 / 10 \mathrm{wt} \%$. The decrease of the elongation after 4, 14 and 24 days is shown in Figure 4: in about one month, the mixture stored at room temperature loses its ductile properties dramatically. A slight increase of Young's modulus, impact strength and tensile strength of the PLA/PHBV blends in time is within the experimental errors and thus is not shown.

In Figure 5, Young's modulus $E$ and tensile strength $S$ of the PLA/PHBV blends are presented as a function of blend composition. The experimental results are shown with points and theoretical predictions 
Table 2. Mechanical properties of PLA/ PHBV compositions

\begin{tabular}{|c|c|c|c|c|}
\hline PLA/PHBV composition & $\begin{array}{c}\text { Stress at break } \\
{[\mathbf{M P a}]}\end{array}$ & $\begin{array}{c}\text { Elongation at break } \\
{[\mathbf{\%}]}\end{array}$ & $\begin{array}{c}\text { Young's modulus } \\
{[\mathbf{M P a}]}\end{array}$ & $\begin{array}{c}\text { Impact strength } \\
{\left[\mathbf{k J} / \mathbf{m}^{2}\right]}\end{array}$ \\
\hline $0 / 100$ & $38.8 \pm 0.4$ & $3.9 \pm 0.6$ & $2310 \pm 80$ & $1.20 \pm 0.20$ \\
\hline $10 / 90$ & $39.8 \pm 0.2$ & $3.8 \pm 0.5$ & $2320 \pm 30$ & - \\
\hline $20 / 80$ & $42.7 \pm 1.2$ & $3.4 \pm 0.2$ & $2380 \pm 50$ & $0.95 \pm 0.30$ \\
\hline $30 / 70$ & $46.1 \pm 0.8$ & $3.7 \pm 0.3$ & $2420 \pm 50$ & - \\
\hline $40 / 60$ & $47.5 \pm 0.6$ & $6.6 \pm 1.1$ & $2410 \pm 20$ & $1.34 \pm 0.18$ \\
\hline $50 / 50$ & $53.6 \pm 0.4$ & $4.1 \pm 0.7$ & $2610 \pm 60$ & - \\
\hline $60 / 40$ & $56.4 \pm 1.0$ & $5.5 \pm 0.9$ & $2610 \pm 60$ & - \\
\hline $70 / 30$ & $57.0 \pm 0.8$ & $9.8 \pm 2.2$ & $2580 \pm 20$ & $2.63 \pm 0.50$ \\
\hline $80 / 20$ & $56.5 \pm 0.8$ & $50.7 \pm 33.4$ & $2490 \pm 70$ & $2.55 \pm 0.55$ \\
\hline $90 / 10$ & $58.0 \pm 0.3$ & $204.3 \pm 20.5$ & $2360 \pm 40$ & $2.00 \pm 0.90$ \\
\hline $100 / 0$ & $67.5 \pm 0.5$ & $4.8 \pm 0.4$ & $2630 \pm 30$ & \\
\hline
\end{tabular}

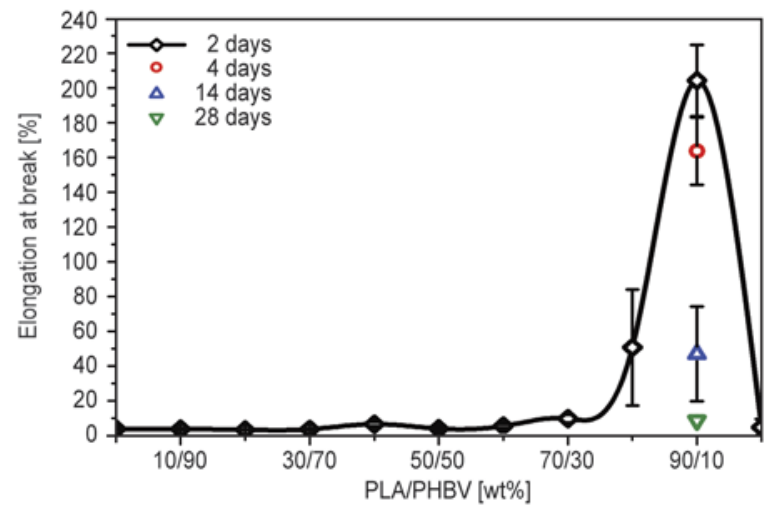

Figure 4. Elongation at break of the PLA/PHBV blends as a function of the blend composition as measured two days after injection. The results of testing the 90/10 wt $\%$ composition after 4, 14 and 28 days are also presented

for $E_{\text {blend }}$ and $S_{\text {blend }}$, calculated according to Voigt (Equation (5)) and Reuss (Equation (6)) models, are given with solid and dashed lines, respectively:

$E_{\text {blend }}=\sum_{\mathrm{i}} f_{\mathrm{i}} E_{\mathrm{i}}, \quad S_{\text {blend }}=\sum_{\mathrm{i}} f_{\mathrm{i}} S_{\mathrm{i}}$

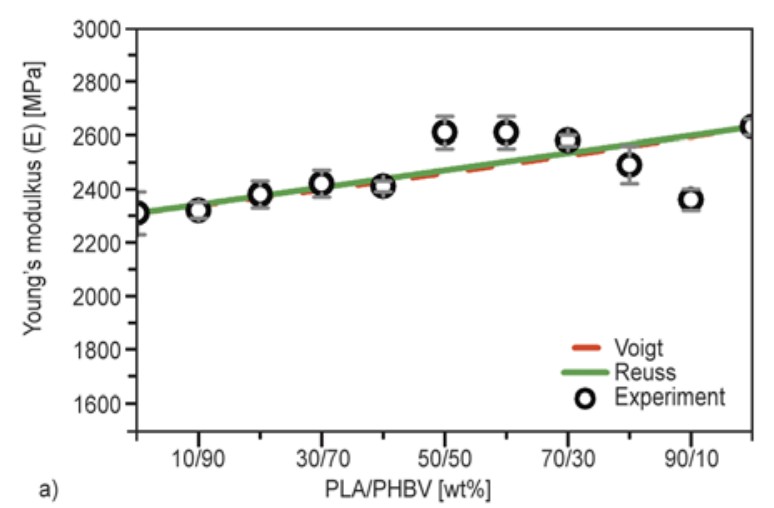

$\frac{1}{E_{\text {blend }}}=\sum_{\mathrm{i}} f_{\mathrm{i}} \frac{1}{E_{\mathrm{i}}}, \quad \frac{1}{S_{\text {blend }}}=\sum_{\mathrm{i}} f_{\mathrm{i}} \frac{1}{S_{\mathrm{i}}}$

where $f_{\mathrm{i}}$ is mass fraction of each component in the blend and $E_{\mathrm{i}}$ or $S_{\mathrm{i}}$ are neat component Young's modulus and tensile strength values, respectively.

It is clear that tensile strength increases with increasing concentration of PLA phase (Figure 5a) and follows, within the errors, the trends predicted by both models. Both give rather similar $S_{\text {blend }}$ values and none of them can be privileged in terms of better matching the experimental data.

Young's modulus of the blends is in-between the values of neat components, from 2300 to $2600 \mathrm{MPa}$ (Figure 5b), and increases, in overall, with increasing of PLA fraction in the blend, except for some blends with low PHBV weight fraction (80/20 and $90 / 10 \mathrm{wt} \%$ ). Because of a very small difference between the moduli of neat PLA and PHBV, both models predict very similar $E_{\text {blend }}$ values. The modulus of the blends with the components in equal proportions, forming co-continuous phases, is slightly above the additive prediction. Because the maxi-

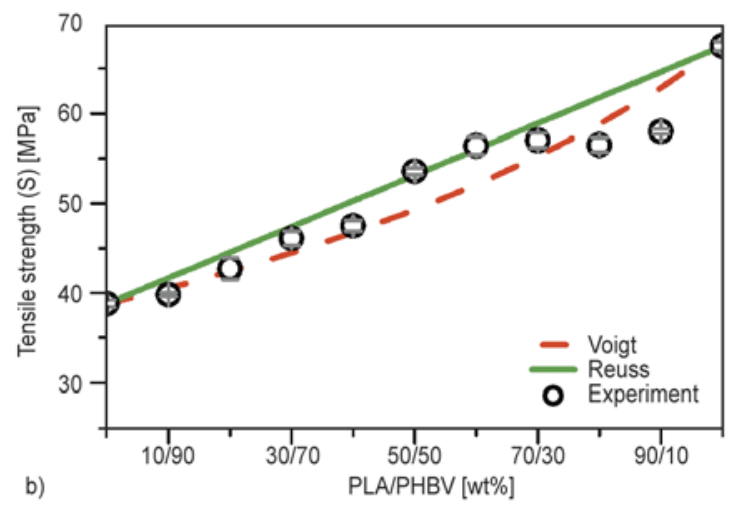

Figure 5. (a) Young's modulus and (b) tensile strength of the PLA/PHBV blends as a function of the blend composition. A comparison with the theoretical predictions (Voight and Reuss models) is also presented with solid green and dashed red lines, respectively. 
mum deviation of experimental values from the predictions given by models is within $10 \%$, we will not speculate about the reason of this slight increase of blend Young's modulus. Blends with low PHBV fraction, such as PLA/PHBV $=80 / 20$ and $90 / 10$, show moduli lower than the additive values, with the maximal deviation from the theoretical prediction being within $15 \%$. One of the reasons of this negative deviation could be that after two days the mixture is still ductile and thus has weaker Young's modulus. As mentioned above, Young's modulus of the blend PLA/PHBV $=90 / 10 \mathrm{wt} \%$ slightly increases in time, practically reaching the additive values.

\section{Conclusions}

The morphological and mechanical properties of fully bio-based blends, PLA/PHBV, prepared by melt mixing, were investigated in details as a function of composition with the increment of $10 \mathrm{wt} \%$ in the full range of compositions. We statistically analyzed blend morphology using their SEM images and applying principles of irreversible thermodynamics. Two statistical ensembles of the minor-phase droplets involving dispersed and coalesced particles were found. When a content of the minor phase was low $(\leq 10 \mathrm{wt} \%)$, only dispersed particles of the minor phase were found, whereas at the higher minorphase concentration, both dispersed and coalesced minor-phase particles were observed. For $50 / 50 \mathrm{wt} \%$ composition, no dispersed particles were found. The mean diameters of both dispersed and coalesced minor-phase particles were calculated and plotted against blend composition. The mean diameter of the dispersed minor-phase particles was shown to be small (about $1 \mu \mathrm{m}$ ) and practically not varying with composition. The mean diameter of the coalesced particles was found to increase more considerably and achieves ca. $5 \mu \mathrm{m}$ for the $50 / 50 \mathrm{wt} \%$ composition exhibiting co-continuous morphology.

Young's modulus and tensile strength of the PLA/ PHBV blends were investigated as a function of blend composition. Both characteristics were found to increase with increasing proportion of the PLA component. The results obtained correspond, within the experimental errors, to the theoretical predictions according to Reuss and Voigt models.

Blends with low content of PHBV in the minor phase showed very high elongation at break, about $200 \%$, for samples studied two days after injection. We found that this property decreases dramatically in one month (from 200 to few \%) because of the aging process in both components, though tensile strength, Young's modulus, and impact strength did not change considerably in time.

\section{Acknowledgements}

The present work is performed in the frame of the Industrial Chair in Bioplastics, organized by CEMEF/MINES ParisTech and supported by Arkema, L'Oreal, Nestlé, PSA Peugeot Citroën, and Schneider Electric. Authors are grateful to Suzanne Jacomet (CEMEF/MINES ParisTech) for the help is SEM experiments.

\section{References}

[1] Garlotta D.: A literature review of poly(lactic acid). Journal of Polymers and the Environment, 9, 63-84 (2001). DOI: 10.1023/A:1020200822435

[2] Conn R. E., Kolstad J. J., Borzelleca J. F., Dixler D. S., Filer L. J., Ladu B. N., Pariza M. W.: Safety assessment of polylactide (PLA) for use as a food-contact polymer. Food and Chemical Toxicology, 33, 273-356 (1995). DOI: 10.1016/0278-6915(94)00145-E

[3] Lasprilla A. J. R., Martinez G. A. R., Lunelli B. H., Jardini A. L., Filho R. M.: Poly-lactic acid synthesis for application in biomedical devices - A review. Biotechnology Advances, 30, 321-328 (2012).

DOI: $10.1016 /$ j.biotechadv.2011.06.019

[4] Rasal R. M., Janorkar A. V., Hirt D. E.: Poly(lactic acid) modifications. Progress in Polymer Science, 35, 338-394 (2010).

DOI: $10.1016 /$ j.progpolymsci.2009.12.003

[5] Holmes P. A.: Biologically produced (R)-3-hydroxyalkanoate polymers and copolymers. Elsevier, London (1998).

[6] El-Hadi A., Schnabel R., Straube E., Müller G., Riemschneider M.: Effect of melt processing on crystallization behavior and rheology of poly(3-hydroxybutyrate) (PHB) and its blends. Macromolecular Materials and Engineering, 287, 363-372 (2002). DOI: $10.1002 / 1439-2054(20020501) 287: 5<363:: A I D-$ MAME363>3.0.CO;2-D

[7] Blümm E., Owen A. J.: Miscibility, crystallization and melting of poly(3-hydroxybutyrate)/ poly(L-lactide) blends. Polymer, 36, 4077-4081 (1995). DOI: 10.1016/0032-3861(95)90987-D

[8] Koyama N., Doi Y.: Miscibility of binary blends of poly $[(R)$-3-hydroxybutyric acid $]$ and poly $[(S)$-lactic acid]. Polymer, 38, 1589-1593 (1997). DOI: $10.1016 / \mathrm{S} 0032-3861(96) 00685-4$ 
[9] Bartczak Z., Galeski A., Kowalczuk M., Sobota M., Malinowski R.: Tough blends of poly(lactide) and amorphous poly([R,S]-3-hydroxy butyrate) - morphology and properties. European Polymer Journal, 49, 3630-3641 (2013).

DOI: 10.1016/j.eurpolymj.2013.07.033

[10] Laycock B., Halley P., Pratt S., Werker A., Lant P.: The chemomechanical properties of microbial polyhydroxyalkanoates. Progress in Polymer Science, 38, 536583 (2013).

DOI: 10.1016/j.progpolymsci.2012.06.003

[11] Ferreira B. M. P., Zavaglia C. A. C., Duek E. A. R.: Films of PLLA/PHBV: Thermal, morphological, and mechanical characterization. Journal of Applied Polymer Science, 86, 2898-2906 (2002).

DOI: 10.1002/app.11334

[12] Ramkumar D. H. S., Bhattacharya M.: Steady shear and dynamic properties of biodegradable polyesters. Polymer Engineering and Science, 38, 1426-1435 (1998). DOI: $10.1002 /$ pen.10313

[13] Wang S., Ma P., Wang R., Wang S., Zhang Y.: Mechanical, thermal and degradation properties of $\operatorname{poly}(d, l$ lactide)/poly(hydroxybutyrate-co-hydroxyvalerate)/poly (ethylene glycol) blend. Polymer Degradation and Stability, 93, 1364-1369 (2008).

DOI: $10.1016 /$ j.polymdegradstab.2008.03.026

[14] Marcilla A., Garcia-Quesada J. C., Lopez M., Gil E.: Study of the behavior of blends of a poly(hydroxybutyrate-valerate) copolymer, polypropylene, and SEBS. Journal of Applied Polymer Science, 113, 3187-3195 (2009).

DOI: 10.1002/app.29939

[15] Sudesh K., Abe H., Doi Y.: Synthesis, structure and properties of polyhydroxyalkanoates: Biological polyesters. Progress in Polymer Science, 25, 1503-1555 (2000).

DOI: 10.1016/S0079-6700(00)00035-6

[16] Modi S., Koelling K., Vodovotz Y.: Miscibility of poly (3-hydroxybutyrate-co-3-hydroxyvalerate) with high molecular weight poly(lactic acid) blends determined by thermal analysis. Journal of Applied Polymer Science, 124, 3074-3081 (2012).

DOI: $10.1002 / a p p .35343$

[17] Boufarguine M., Guinault A., Miquelard-Garnier G., Sollogoub C.: PLA/PHBV films with improved mechanical and gas barrier properties. Macromolecular Materials and Engineering, 298, 1065-1073 (2013)

DOI: $10.1002 /$ mame.201200285

[18] Gerard T., Budtova T.: Morphology and molten-state rheology of polylactide and polyhydroxyalkanoate blends. European Polymer Journal, 48, 1110-1117 (2012).

DOI: $10.1016 /$ j.eurpolymj.2012.03.015

[19] Nanda M. R., Misra M., Mohanty A. K.: The effects of process engineering on the performance of PLA and PHBV blends. Macromolecular Materials and Engineering, 296, 719-728 (2011).

DOI: $10.1002 /$ mame.201000417
[20] Zhao H., Cui Z., Wang X., Turng L-S., Peng X.: Processing and characterization of solid and microcellular poly(lactic acid)/polyhydroxybutyrate-valerate (PLA/ PHBV) blends and PLA/PHBV/clay nanocomposites. Composites Part B: Engineering, 51, 79-91 (2013). DOI: 10.1016/j.compositesb.2013.02.034

[21] Hufenus R., Reifler F. A., Maniura-Weber K., Spierings A., Zinn M.: Biodegradable bicomponent fibers from renewable sources: Melt-spinning of poly(lactic acid) and poly[(3-hydroxybutyrate)-co-(3-hydroxyvalerate)]. Macromolecular Materials and Engineering, 297, 75-84 (2012).

DOI: $10.1002 /$ mame.201100063

[22] Kilian H. G., Zink B., Metzler R.: Aggregate model of liquids. Journal of Chemical Physics, 107, 8697-8705 (1997). DOI: $10.1063 / 1.475022$

[23] Kilian H-G., Bronnikov S., Sukhanova T.: Transformations of the micro-domain structure of polyimide films during thermally induced chemical conversion: Characterization via thermodynamics of irreversible processes. Journal of Physical Chemistry: B, 107, 13575-13582 (2003).

DOI: $10.1021 / \mathrm{jp} 035074 \mathrm{~m}$

[24] Zuev V. V., Bronnikov S.: Statistical analysis of the phase separation of LDPE/PA-6 blends compatibilized with SEBS- $g$-MA and/or organoclays. Journal of Polymer Research, 17, 731-735 (2010).

DOI: $10.1007 / \mathrm{s} 10965-009-9363-y$

[25] Zuev V. V., Bronnikov S.: Statistical analysis of morphology of low density polyethylene/polyamide 6 blends with addition of organoclay and maleic anhydride-grafted polystyrene- $b$-poly(ethylene-co-butene1)- $b$-polystyrene copolymer as compatibilizers. Journal of Macromolecular Science Part B: Physics, 51, 1558-1565 (2012).

DOI: $10.1080 / 00222348.2012 .656008$

[26] Zuev V. V., Steinhoff B., Bronnikov S., Kothe H., Alig I.: Flow-induced size distribution and anisotropy of the minor phase droplets in a polypropylene/poly (ethylene-octene) copolymer blend: Interplay between breakup and coalescence. Polymer, 53, 755-760 (2012).

DOI: $10.1016 /$ j.polymer.2011.12.046

[27] Chen X-H., Yu P., Kostromin S., Bronnikov S.: Minorphase particles evolution in a polyethylene/ethylenepropylene copolymer (80/20) blend across mixing: Breakup and coalescence. Journal of Applied Polymer Science, 130, 3421-3431 (2013).

DOI: $10.1002 / a p p .39373$

[28] Tang W., Wang H., Tang J., Yuan H.: Polyoxymethylene/thermoplastic polyurethane blends compatibilized with multifunctional chain extender. Journal of Applied Polymer Science, 127, 3033-3039 (2013). DOI: $10.1002 / a p p .37538$ 
[29] Imre B., Renner K., Pukánszky B.: Interactions, structure and properties in poly(lactic acid)/thermoplastic polymer blends. Express Polymer Letters, 8, 2-14 (2014).

DOI: 10.3144/expresspolymlett.2014.2

[30] Noda I., Satkowski M. M., Dowrey A. E., Marcott C.: Polymer alloys of Nodax copolymers and poly(lactic acid). Macromolecular Bioscience, 4, 269-275 (2004). DOI: 10.1002/mabi.200300093

[31] Zhao Q., Wang S., Kong M., Geng W., Li R. K. Y., Song S., Kong D.: Phase morphology, physical properties, and biodegradation behavior of novel PLA/PHBHHx blends. Journal of Biomedical Materials Research Part B: Applied Biomaterials, 100, 23-31 (2012).

DOI: 10.1002/jbm.b.31915
[32] Pan P., Zhu B., Inoue Y.: Enthalpy relaxation and embrittlement of poly(L-lactide) during physical aging. Macromolecules, 40, 9664-9671 (2007).

DOI: $10.1021 / \mathrm{ma} 071737 \mathrm{c}$

[33] Srubar III W. V., Wright Z. C., Tsui A., Michel A. T., Billington S. L., Frank C. W.: Characterizing the effects of ambient aging on the mechanical and physical properties of two commercially available bacterial thermoplastics. Polymer Degradation and Stability, 97, 19221929 (2012).

DOI: $10.1016 /$ j.polymdegradstab.2012.04.011 